he/she be made helpless? If, Social Services are loathe to displace relatives as the next of kin, we as clinicians ought to highlight this reluctance in joint meetings with Social Services. I would also disagree that once initiated, the process is long and complicated. Given its seriousness it is of necessity time-consuming involving submission of a report and possible court appearances, but our primary concern must remain the patients, whether or not we perceive the relatives as awkward or difficult. One of the strengths of the current Mental Health Act is that the rights of individuals and of the nearest relative are protected.

My colleagues from Social Services and I have recently been involved in a case where it became necessary to ask the court to displace a young lady's mother as next of kin on the grounds that she unreasonably objected to making an application for treatment. The court agreed with our views and the nearest relative was displaced. Since then the relationship between the displaced relative and the clinicians has improved dramatically!

Corby Mental Health Team

SEAN SCanlon

Central Clinic

Corby, Northants. NN17 IRJ

\section{Mental state at discharge}

DeAr Sirs

We are in complete agreement with Akerman \& McCarthy (Psychiatric Bulletin, April 1992, 16, 216-217) that mental state at discharge should be included in all discharge communications from hospital. The authors highlight the contribution such a record could make to formal audit. A record of mental state at discharge has several other important benefits: it focuses the mind of the clinician on the therapeutic process which has just occurred, thus, encouraging him(her) to audit the care he(she) has delivered; it helps other health care workers assess future changes in the patient's mental state; it helps future clinicians plan more effective treatments by giving an explicit indication of therapeutic response (rather than the usual implicit assumption that the patient probably improved if he/she was discharged); and it is very useful in retrospective case note research. We believe that recording mental state at discharge should be part of routine psychiatric practice and we hope that if we repeated our audit of discharge summaries (Craddock \& Craddock, 1990) in five years' time that we would find this item recorded in significantly more than one quarter of summaries.

Nick Craddock

Queen Elizabeth Psychiatric Hospital

BRIDGET CRADDOCK

Birmingham B15 2QZ

\section{Reference}

Craddock, N. \& Craddock, B. (1990) Audit of psychiatric discharge summaries. Psychiatric Bulletin 14, 618-620.

\section{Violence and junior psychiatrists}

\section{DEAR SIRS}

Drs Kidd and Stark (Psychiatric Bulletin, March 1992, 16, 144-145) have addressed a potentially important area of concern to us all, particularly in the wake of the CTC working party recommendations with respect to violent incidents (1991). My concern is that they have perhaps not gone far enough.

The Health Services Advisory Committee report (1987) stated that although defining violence is difficult, it is an essential task for anyone involved in the management and prevention of violent incidents. I believe the same applies to those engaged in research in this field. Drs Kidd and Stark fail to define what they mean by "physical assault" or "imminent danger". Assault in law means reasonable fear or apprehension of the unjustified use of force. Any unwanted contact is a battery. These definitions are themselves limited in their usefulness but what is urgently required, if we are to represent the problem accurately and reach a sensible conclusion, are specific and detailed data. The circumstances of each incident, the physical environment in which it took place and the state of mind of the assailant, are vital pieces of information if any meaningful attempt at prevention is to be made. This is not to confuse the issue with that of the prediction of dangerousness, but merely to recognise that assaultive behaviour is complex and depends upon many factors, and if we choose not to acknowledge this then we run the risk of misrepresenting the facts, and doing both ourselves and our patients a grave disservice. For instance, major mental disorder leads to violence far less frequently than intoxication with alcohol or other substances. The relationship between mental illness and violence is far from clear and forms the basis of much current research. Psychiatrists should be aware of the possibility of fuelling public misconceptions about the "dangerous madman".

The authors make the point that following 20 out of a total of 28 incidents, no support was offered. This is hardly surprising in light of the fact that only five were reported. The reasons for failure to report the other 23 episodes would have been of interest for as Barczak \& Gohari (1988) pointed out, there are wide-ranging implications from this, for staff and patients alike, and even when an efficient system of care for victims exists, problems arise as staff are reluctant to use it.

The opening statement of the article that "aggression directed towards health care workers has been 